\title{
Geodynamic Hazard Factors of Latvia: Experimental Data and Computational Analysis
}

\author{
Valērijs N̦IKUL̦INS \\ Latvian Environment, Geology and Meteorology Centre, Maskavas Str. 165, Riga, Latvia \\ University of Latvia, Faculty of Geography and Earth Sciences, Jelgavas Str. 1, Riga, Latvia \\ valerijs.nikulins@lvgmc.lv
}

\begin{abstract}
Geodynamic hazards of Latvia were identified by experimental and computational methods, including tectonophysical modeling in the MathLab environment. Among these factors are seismic shocks in Riga on November 22, 2010, abnormally high velocity of displacement of opposite sides of the Cirulisi fault, an increased anomaly of radon concentration on the profile crossing Olaine-Incukalns fault, deformations of buildings in the tectonic zone, formed by OlaineIncukalns and Bergi faults. An analysis of the isostatic equilibrium of the Earth's crust at the Moho discontinuity level allowed to estimate Earth's crust development's and tendency type. On the basis of the analysis of experimental data and the results of tectonophysical modeling, a depression site was discovered in the area at the Plavinas dam. The conclusion is made about the expediency of geodynamic monitoring in areas of large agglomerations (Riga) and especially responsible objects (Plavinas dam, Incukalns underground gas storage).
\end{abstract}

Key words: geodynamics, seismotectonics, Earth's crust, isostatic index, tectonophysical modeling, Persistent Scatterer Interferometry.

\section{Introduction}

The main factors determining the geodynamic activity of a particular territory are the following: 1) proximity to the boundaries of tectonic plates; 2) the type of the boundary between tectonic plates; 3) geological situation (platform, geosyncline area); 4) the influence of exogenous factors (glacial load) and the reaction of Earth's geospheres (restoration of isostatic equilibrium); 5) the orientation of the maximum horizontal compressive stresses.

The territory of Latvia is located in the north-west of the ancient, Precambrian East European craton (EEC). In the west-southwest the EEC borders on the younger and more active Phanerozoic orogen of Western Europe (POWE). The border between platforms is the Teisseyre-Tornquist zone, from which Latvia is located at a distance of about 375 $\mathrm{km}$. The distance to the nearest divergent boundary located in the North Atlantic (DBNA) is about $1840 \mathrm{~km}$, and to the nearest convergent boundary located in the Mediterranean Sea (CBMS) - about $1870 \mathrm{~km}$. The divergent boundary it is constructive boundary where two tectonic plates are moving away from each other and new crust is 
formed. The convergent zones it is the destructive plate boundary where two or more tectonic plates or fragments of the lithosphere are near the end of their life cycle. The main influence on the formation of the geodynamic situation on the territory of Latvia and the East-Baltic region (EBR) is exerted by the DBNA, from which there is pressure in the southeast direction.

The dynamics of the Earth's crust is largely determined by the deep processes that play a leading role in its evolution. The processes of disturbance of the hydrostatic equilibrium state of the earth's crust have a significant effect on the dynamics of the Earth's crust, i.e. isostatic equilibrium. The study of the parameters of the isostatic equilibrium of the Earth's crust allows us to assess the trend of its development. The conditions for such assessments appeared in Latvia and the EBR, thanks to earlier studies of the earth's crust using the method of deep seismic sounding (Ankudinov et al., 1991).

Important modern features are the modern vertical movements, radon anomalies, seismotectonic processes. These factors and processes were analyzed for Riga and Riga region, as well as for the Plavinas HPP area and the head part of the reservoir. In the latter case, tectonophysical modeling was used to understand the geodynamic processes, which allowed obtaining a characteristic of the motion of the Earth's crust.

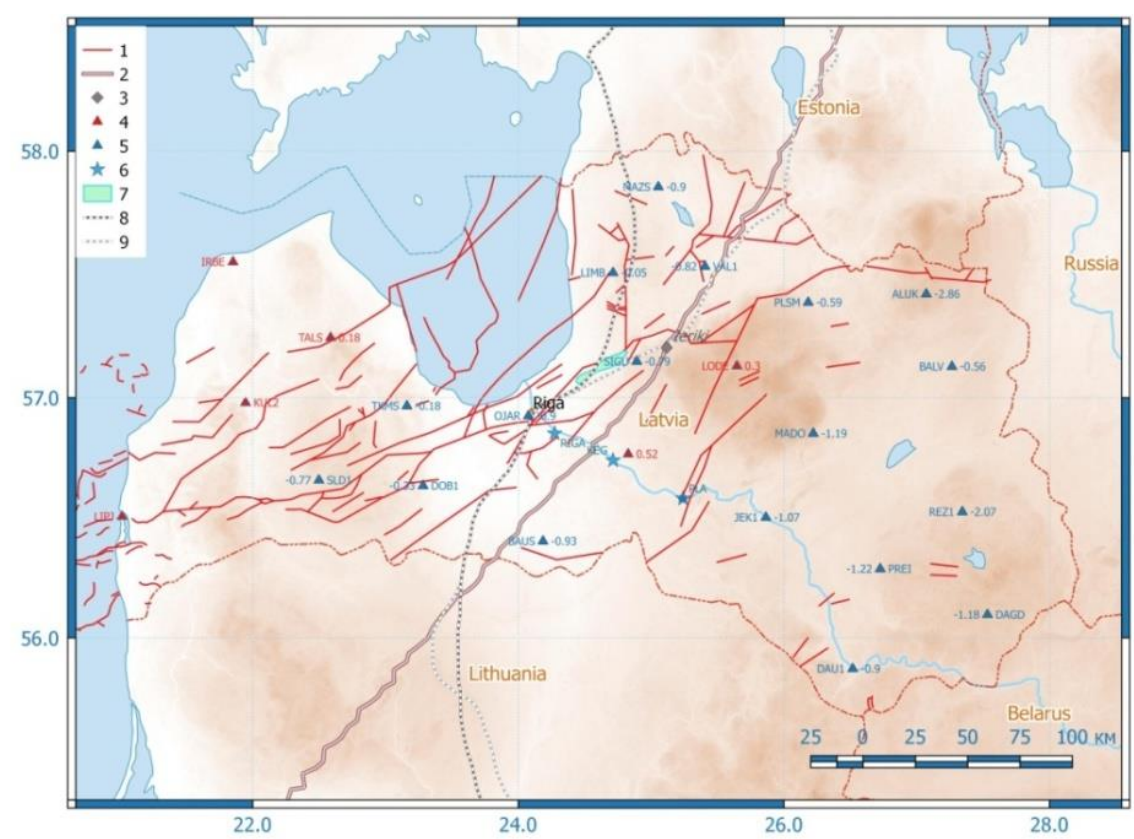

Fig. 1. Profile of deep seismic sounding Sovetsk-Riga-Kohtla-Jarve on the basis of a surface relief map and main objects of the energy and transport infrastructure of Latvia. Designations: 1 tectonic faults in the Caledonian structural complex; 2 - profile of the DSS Sovetsk-Riga-KohtlaJarve; 3 - Ieriki; 4 - positive values of the GPS offset velocity at LatPos network stations; 5 negative values of the GPS offset velocity at LatPos network stations; 6 - hydroelectric power stations; 7 - Incukalns underground gas storage facility; 8 - the main project of the Rail Baltica railway; 9 - alternative project of the Rail Baltica railway. 


\section{Methods and materials}

\section{Method for estimating of isostatic state violation}

The deep crustal structure of the EBR was studied on the basis of the deep seismic sounding (DSS) method along the Soviet-Riga-Kohtla-Jarve profile (Figure 1).

These results (Ankudinov et al., 1991) allowed to obtain the main reflecting boundaries in the Earth's crust and upper mantle and to study the block structure of the Earth's crust. Modeling the gravitational influence of various layers of the Earth's crust allowed investigators Ozolina and Kovrigin in 1986 to obtain estimates of physical properties of rocks. These estimates were used to create a model of the isostatic state of the Earth's crust (isostatic index) in the EBR at the Moho discontinuity level (A equilibrium).

Complex analysis of the deep geological structure, gravitational field $(\Delta g)$ (based on the report of Ozolina and Kovrigin in 1986), density of heat flow $(Q)$ (based on the report of Zazimko and Sokurenko in 1994), amplitudes of neotectonic movements $\left(A_{N}\right)$, starting with Rupelian (Garetsky et al., 1999), velocity of modern vertical movements $\left(V_{V}\right)$ (based on the report of Kovalevsky and others in 1966) allowed to investigate the relationship with isostatic index.

As is known, isostasy is a hydrostatic equilibrium state of lithospheric blocks, when less dense blocks "float" in a denser layer of the upper mantle, obeying Archimedes' law. Classical models of isostasy cover large areas of the lithosphere $(100-200 \mathrm{~km})$, when pressure equalization occurs at some depth of compensation $(P$ - model). In particular, such a compensation boundary in the Airy-Heiskanen model corresponds to the relief of the "roots of the mountains", in Pratt-Hayford model to some stationary depth, and in the Vening Meinesz model of the spherical surface.In Airy-Heiskanen model different topographic heights are accommodated to changes in crustal thickness, in which the crust has a constant density. In Pratt-Hayford model different topographic heights are accommodated by lateral changes in rock density. In Vening Meinesz as flexural isostasy model the lithosphere acts as an elastic plate and its inherent rigidity distributes local topographic loads over a broad region by bending.

For estimating the isostatic state of small blocks, a model of the equilibrium state of the earth's crust at the level of the Moho discontinuity boundary was proposed (Faytelson, 1973). The criterion for disturbing the hydrostatic equilibrium Earth's crust was the isostatic index $\Delta m$, which characterizes the stability of the Earth's crust and its propensity to move relative to the Moho discontinuity.

The conditions of equilibrium of the Earth's crust at the level of the Moho discontinuity can be represented in the following form:

$$
\begin{gathered}
m_{M}-m_{C}=\Delta m \\
-\rho_{m} h_{t}+\sum \Delta \rho_{m i} H_{i}=\Delta m \\
-\rho_{m} h_{t}+\Delta \rho_{m w} H_{w}+\rho_{m s} H_{S}+\Delta \rho_{m g} H_{g}+\Delta \rho_{m b} H_{b}=\Delta m
\end{gathered}
$$


where $m_{M}-$ mantle mass displaced by the Earth's crust; $m_{C^{-}}$crust mass; $\Delta m-$ crust isostatic equilibrium index ( $A$-model); $h_{t}=h+T_{0} ; h$ - altitude of the area; $T_{0}$ - the assumed absolute depth up to mantle in the absence of load - crust; $\Delta \rho_{m i}=\rho_{m}-\rho_{i}$; $\Delta \rho_{m w}=\rho_{m}-\rho_{w}$, where $\rho_{m}, \rho_{i}, \rho_{w}, \rho_{S}, \rho_{g}, \rho_{b}$ - density of the upper mantle (index $m$ ), $i$-water layer $(w)$, precipitation $(S)$, "granite" layer $(g)$ and "basaltic" layer $(b), H_{i}, H_{w}$, $H_{S}, H_{g}, H_{b}-$ thickness of the Earth's crust layers.

The physical meaning $\Delta m$ expresses the difference in the masses of the Earth's crust and mantle per unit area, when in the vertical column of the geological substrate the mantle mass displaced by the Earth's crust $\left(m_{M}\right)$ is not equal to the mass of the earth's crust $\left(m_{C}\right)$ in accordance with expression 1.

The index of disturbance of the equilibrium of the Earth's crust is a convenient characteristic for assessing the types of the Earth's crust and the direction of its evolution. In the direction of the development of the earth's crust, two types of processes are distinguished (Figure 2), which constantly disrupt the Archimedean equilibrium of the cortex in the upper mantle (Rezanov and Faytelson, 1973). Each type has its own lead process.

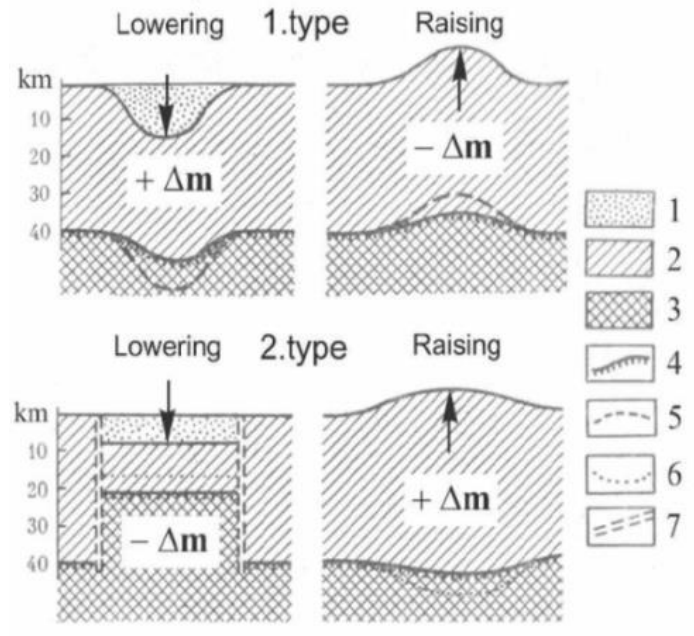

Fig. 2. Types of development of the Earth's crust and the direction of change in their capacity. Designations: 1 - precipitation; 2 - consolidated bark; 3 - upper mantle; 4 - the Moho discontinuity; 5 - the supposed position of the Moho discontinuity, in the case when the equivalent lowering or raising of the Moho discontinuity corresponds to the subsidence or lifting of the Earth's surface (type I of development); 6 - the supposed position of the Moho discontinuity, if the displacement of the Moho discontinuity along the section (type II of development) is not accompanied by a counter-lowering or rising of the entire crust; 7 - fault.

In the first type of development of the crust, leading process it is motion (moving) up or down the vertical of the entire crust, starting from the Moho surface to the day surface. The whole crust bends, or rises, i.e. Earth's surface repeats the motion of the 
Moho discontinuity. In fact, the crustal uplifts usually correspond to more a deep, but the immersions correspond to a less deep position of the Moho discontinuity. In Fig. 1 the supposed position of the Moho discontinuity is indicated by a dashed line, and the real position by a solid line. Thus, the leading process that disturbs the equilibrium of the Earth's crust is expressed in raising or lowering the entire crust as a whole, and a change in the thickness of the crust from below is a compensatory process aimed at restoring its equilibrium.

In the second type of crustal development, the leading process is the process of moving up or down Moho discontinuity. A change in the thickness of the Earth's crust leads to an increase in the crust, or to a decrease and violation of the Archimedean equilibrium. Arise isostatic movements which aimed at restoring its equilibrium.

Thus, the main difference between these two types of crustal development is that in the first case the entire crust as a whole moves, whereas in the second case the crustal thickness changes from below, and the Earth's surface moves in the opposite direction.

\section{Interferometric synthetic-aperture radar (InSAR) method for studying modern vertical movements}

The modern vertical movements of the Earth's crust for the territory of Riga and Liepaja have been studied by the InSAR method within the framework of the PanGeo Project. InSAR is a radar method used in geodesy and remote sensing. InSAR uses two or more radar images with synthetic aperture $(S A R)$. This is necessary to create surface strain maps or digital heights using differences in the phase of the waves that are returned to the satellite. For city conditions, the most optimal modification of InSAR is PSI (Persistent Scatterer Interferometry), which allows to investigate the geological hazard. Radars emitting and receiving microwave electromagnetic radiation $\left(f=10^{8}\right.$ $10^{11} \mathrm{~Hz}$ ) are used around the clock, regardless of the weather. Radar signals are reflected back to the satellite from objects with high reflectivity (reinforced concrete blocks, roofs of houses, truss bridges, railway rails, etc.). The radar illuminates the surface of the Earth with a beam of coherent microwave radiation $(\lambda=5.66 \mathrm{~cm})$, which can penetrate through the clouds. The main measured parameter is the phase difference for each Persistent Scatterer (PS point) for different directions of flight by a satellite in this area. The constant phase difference indicates a stable position of the reflector, whereas a change in the phase difference indicates its movement. The general form of the interferogram consists of the following components:

$$
\Delta \phi=\phi_{\text {base }}+\phi_{\text {topo }}+\phi_{\text {defo }}+\phi_{\text {atm }}+\phi_{\text {noise }}
$$

where, $\phi_{\text {base }}$ - the phase difference for the baseline between the positions of the satellite corresponding to the two acquisitions; $\phi_{\text {topo }}$ - topography; $\phi_{\text {defo }}$ - deformation of soil; $\phi_{\text {atm }}$ - atmospheric delay; $\phi_{\text {noise }}$ - other conditions, including ionospheric effects and system noise.

The quality criterion is the standard deviation $(S T D E V)$ and the coherence coefficient $\left(K_{c o h}\right) . S T D E V$ for velocity of moving PS points reaches $0.40-0.53 \mathrm{~mm} / \mathrm{year}$, and for the time series of displacements $-1.1-4.0 \mathrm{~mm}$. The standard deviation for topographic correction is $2.14-4.71 \mathrm{~m}$ (Bateson et al., 2010). On the territory of Riga, 64115 PS 
points were identified, with an average density of $\sim 70$ points $/ \mathrm{km}^{2}$. The time series of observations covers the period from 8.08.1992 to 24.10.2000. During this time, 53 times the ERS-1 / ERS-2 satellite overflew of territory.

\section{Method for studying anomalies of radon concentration in the surface air}

The radon concentration was assessed on three test sites in Latvia: Talsi, Riga and Sigulda, under a Contract with the Ministry of Regional Development and Environment (based on the report of Gilucis in 2014). Among the research tasks included the assessment of geological conditions that could affect the elevated level of radon, as well as identifying places on which there could be an elevated level of radon. The main attention was paid to such geological factors as geochemical, lithological and granulometric composition. Also, the influence of the flow direction of the last glacier during the Holocene and sources of extracted materials was noted (based on the report of Gilucis in 2014). However, the relationship between radon concentration and the tectonic structure and tectonic faults has not been analyzed. The influence of the tectonic factor was recognized as unlikely due to the fact that the crystalline basement lies at a depth of $\sim 400-1800 \mathrm{~m}$.

Measurements of the radon concentration were carried out on three experimental sites measuring $\sim 150-300 \mathrm{~km}^{2}$. A set of measuring instruments ALPHA GUARD PQ 2400 was used. The accuracy of the measurements was $2 \mathrm{~Bq} / \mathrm{m}^{3}$ for the measurement interval from 5 to $100000 \mathrm{~Bq} / \mathrm{m}^{3}$. During the measurements, the soil air was extracted from a depth of 50 to $70 \mathrm{~cm}$, with a production rate of 0.5 to 1.0 liter/min. The depth of measurements was determined by the upper horizon of the soil and the prevalence of the alluvial horizon in the territory of Latvia. The minimum required depth is about $20 \mathrm{~cm}$ below the soil layer and the optimum depth is $10 \mathrm{~cm}$ under the alluvial horizon. In the extracted air, the measurements were carried out with a discreteness of 1 measurement for 1 minute, and the total duration of the measurements reached 10-20 minutes. Each discrete measurement consisted of two separate measurements: 10 seconds at the beginning and 30 seconds at the end. In total, 20 measurements were performed in each individual experiment. This was necessary to obtain statistically significant values.

\section{The method of macroseismic research in Riga in 2010}

Macroseismic research included posting information about jolts on the popular Internet resource Delfi, as well as directly distributing questionnaires among eyewitnesses of seismic concussions. The questionnaire contained questions about the place, time and external effects that eyewitnesses could observe during seismic shocks. In particular, questions were raised about sound and light effects to exclude man-made explosions that could be mistaken for a tectonic earthquake. The intensity was assessed on the EMS-98 scale. A total of 7 questionnaires were received. Such a small number of questionnaires is due to the fact that seismic concussions of low intensity (II - III points) occurred during daytime, working hours. They could to feel only by people who were in a quiet state, or on the upper floors of buildings. 


\section{Method of tectonophysical modeling}

To understand the geodynamic conditions, it is necessary to have estimates of static displacements, strains and stresses at different fault depths, which are caused by the slip of the opposite sides of the fault. For tectonophysical modeling was used program Coulomb, implemented in the MathLab environment. Coulomb is designed to calculate the internal deformation fields for a multiple source, which can be arbitrarily composed of shear and tensile faults, for both point and finite rectangular types.

According to the basic hypothesis of the destruction of the Coulomb, damage develops under the following condition:

$$
\Delta \sigma_{f}=\Delta \tau_{s}+\mu^{\prime} \Delta \sigma_{n}
$$

where, $\Delta \sigma_{f}$ is the stress change on the analysed fault caused by sliding on the source fault; $\Delta \tau_{s^{-}}$change of shear stress; $\mu^{\prime}$ - effective coefficient of friction on the fault; $\Delta \sigma_{n^{-}}$ change in normal stress.

The mechanism of the tectonic fault can be represented in the form shown in Fig. 3.

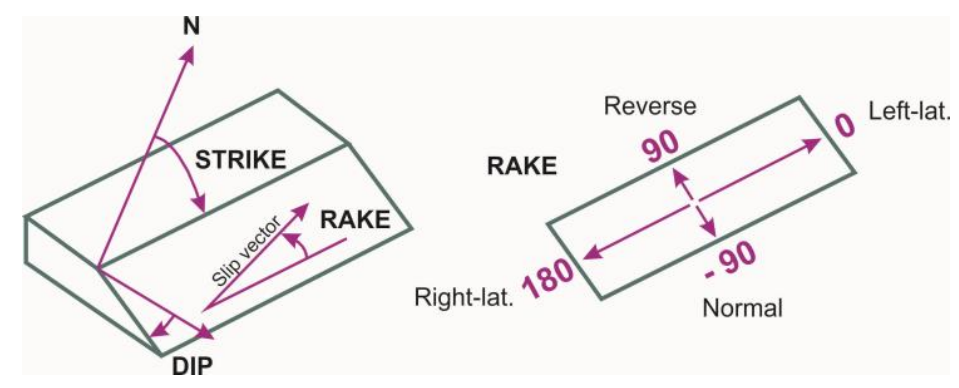

Fig. 3. Elements of a tectonic fault for the solution of focal mechanisms.

The main characteristics of the fault mechanism are: STRIKE - trend or bearing, relative to North, of the line defined by the intersection of a planar geologic surface (for example, a fault or a bed) and a horizontal surface such as the ground, DIP - inclination of a planar geologic surface from the horizontal (measured in degrees), RAKE - the inclination, falling in the fault plane. The boundary values of these parameters: $0^{\circ} \leq$ STRIKE $<360^{\circ} ; 0^{\circ}<D I P \leq 90^{\circ} ;-180^{\circ} \leq R A K E \leq 180^{\circ}$.

Tectonophysical analysis was used to assess the stress-strain state of the Earth's crust in the area of Plavinas HPP and the head part of the reservoir. Tectonophysical analysis was performed for different depths of the Earth's crust: 0.0, 0.02, 0.1, 0.5, 1.0, 3.0 and $5.0 \mathrm{~km}$. The upper level of $0.0 \mathrm{~km}$ is of practical importance, because allows us to compare getting estimates with the observed results. The $0.02 \mathrm{~km}$ level corresponds to the average depth of the Devonian roofing in the analyzed territory. The lower level of $5.0 \mathrm{~km}$ is determined by the depth of the lower edge of tectonic faults. This level was chosen based on experimental estimates of the depth of occurrence of faults in Latvia and on the East European platform. The depth of $1 \mathrm{~km}$ corresponds to the average depth of the crystalline basement. The depths $0.1,0.5$ and $3.0 \mathrm{~km}$ are intermediate depths for which the displacement calculations also were made. These depths are chosen in order to better understand the patterns of change in displacement with increase in depth. 


\section{Results}

\section{Isostatic prerequisites for geodynamic activity}

The results of the assessment of the isostatic state of the Earth's crust at the Moho discontinuity showed that the isostatic index $\Delta m$ continuously increased from picket 150 to picket 390 (Figure 4), from south-west to north-east. In the area of picket 390, the isostatic index $\Delta m$ reaches a maximum value of $6.0 \mathrm{~kg} / \mathrm{mm}^{2}$, and then it decreases to a picket of 500, where it practically stabilizes. In the vicinity of the $\Delta m$ maximum, a good correlation is observed with the density of the heat flow $Q$, the amplitudes of neotectonic motions $A_{N}$, and the velocities of modern, vertical motions $V_{V}$ (Figure 4).

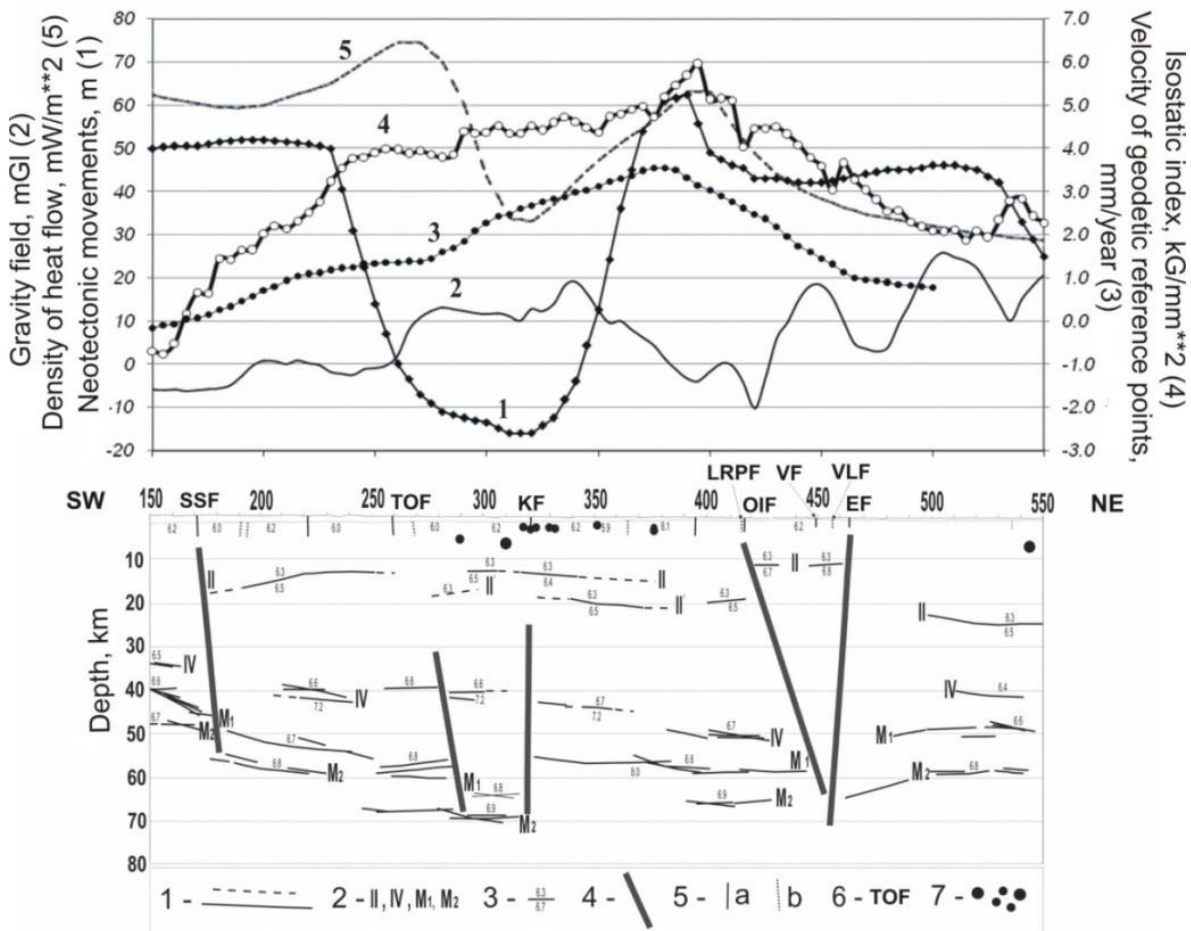

Fig. 4. Deep structure of the earth's crust and upper mantle in the EBR and geological and geophysical parameters along the Sovetsk-Riga-Kohtla-Jarve DSS profile. Designations on the upper graph: 1 - total amplitudes of neotectonic movements in m, starting with Rupelian (Garetsky et al., 1999); 2 - relative observed gravitational field, $\mathrm{mGl} ; 3$-velocity of modern vertical movements of the Earth's crust, mm/year; 4 - isostatic index, $\mathrm{kg} / \mathrm{mm}^{2}$ (Nikulin, 1999); 5 - density of heat flow, $\mathrm{mW} / \mathrm{m}^{2}$. Legend for deep section: 1 - boundaries in the Earth's crust and upper mantle (confident and presumed); 2 - indices of the boundaries in the Earth's crust and upper mantle; 3 - average (top) and boundary (bottom) velocities of body seismic waves, $\mathrm{km} / \mathrm{sec} ; 4$ deep tectonic faults in the Earth's crust and upper mantle; 5 - tectonic faults penetrating (a) and non-penetrating (b) in sedimentary cover; 6 - abbreviation of tectonic faults; 7 - hypocenters of earthquakes. Designations of faults: SSF - South Silale, TOF - Taurage-Ogre, KF - Kekava, LRPF - Liepaja-Riga-Pskov, OIF - Olaine-Incukalns, VF - Valmiera, VLF - Valka, EF - Ergeme. 
At the anomalous area, the Moho discontinuity is located at a depth of $57-59 \mathrm{~km}$ (Figure 4), i.e. deeper than the average depth of $44-45 \mathrm{~km}$ of the Moho discontinuity for the EBR. The DSS profile passed along the north-north-western border of the Vidzeme Upland. On this section of the Vidzeme Upland, the terrain is characterized by an elevated surface with elevations of up to $200 \mathrm{~m}$, while the lowland, located to the northwest has average marks of about $100 \mathrm{~m}$.

Thus, the tendency of the development of the Earth's crust between the pickets 375 410 (Ieriki in Figure 1) corresponds to the II type of Earth's crust development. In this case the leading process is stipulates motion of Moho boundary down and motion of Earth's surface up, consequently moving of these boundaries go in opposite directions. So the isostatic index is positive.

Comparison of the isostatic index $\Delta m$ with geological-geophysical and deformation parameters showed its close connection with the velocities of modern vertical movements $V_{V}$ for the Latvian territory, as well as the coincidence with the maximum values of amplitude of neotectonic movements $A_{N}$ and local maximum of the heat flow $Q$ (Figure 4). Neotectonic and modern uplifts indicate the inherited and positive character of the Earth's crust movement in this region.

The largest underground gas storage in Incukalns and transport infrastructure of the Rail Baltica railway are located (Figure 1) in the immediate vicinity of the section of the Earth's crust with the II type of its development and an abnormal rate of elevation in Ieriki area.

\section{Seismic shocks in Riga and the Riga region November 22, 2010}

Macroseismic studies have shown that three points (points 1 to 3 at Figure 5) in which shocks were felt are located in the north-west of Riga, in the districts of Ilguciems, Kurzeme Avenue and Ulmana alley. In some of these points, the shock was felt much later than the average time ( $\sim 12$ hours) noted at other points. The four points in which the shock was felt are located in the tectonic zone formed by the Olaine-Incukalns and Bergi faults (points 4-7 at Figure 5). The intensity of tremors is estimated as II - III degree on the EMS-98 scale.

The Olaine-Incukalns fault is the longest fault of Latvia, stretching more than $130 \mathrm{~km}$ from the south-west to the northeast, and in the Cesis area, changing its direction to the east, towards Pskov. This fault, unlike other tectonic faults, was better studied, in connection with the creation of an underground gas storage facility adjacent to it in the Ragana area. The Olaine-Incukalns fault is the predominant thrust mechanism with a strike-slip component, while most other faults in Latvia are normal faults (Brangulis and Kanevs, 2002) or prevailing normal fault with strike-slip component.

According to eyewitnesses, a change in the color of the Kalkugrvas water sources of the Allazi district was noted (point 8). In one of the questionnaires, the respondent noted a change in the properties of the spring water ("the water became a bit yellowish") a day before the shock, i.e. November 21. Kalkugravas water springs are located about $9 \mathrm{~km}$ from the Olaine-Incukalns fault and $4.5 \mathrm{~km}$ from the Kekava fault. Numerous studies indicate that changes in hydrogeochemical parameters can occur before earthquakes (Claesson et al., 2004; Barberio et al., 2017; Chaudhuri et al., 2013). However, these changes were characteristic of earthquakes with a magnitude greater than 5.5.However, great importance is the distance from the source of the earthquake to the place where the change in hydrogeochemical parameters was noted. According to studies of the relationship between the magnitude of the earthquake and the precursor's occurrence, an 
earthquake's precursors with a minimum magnitude of 3.5 to 3.6 appears 7 to 8 days before the earthquake (Chaudhuri et al., 2013).

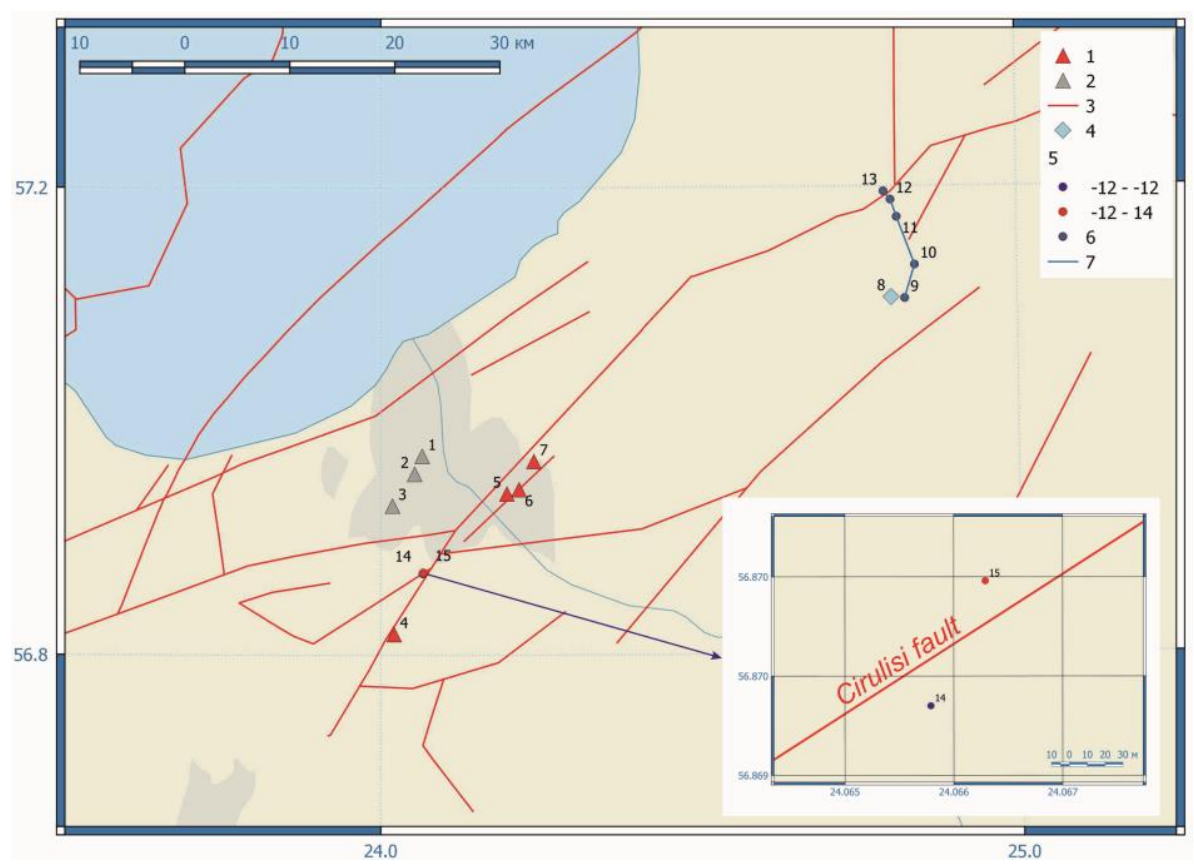

Fig. 5. Seismic shocks in Riga and the Riga region on November 22, 2010, Persistent Scatterer points on the Cirulisi fault and the profile of the radon concentration observation points crossing the Olaine-Incukalns fault. Designations: 1 - points in which shocks were felt within of zone formed by the Olaine-Incukalns and Bergi faults; 2 - points in which shocks were felt in other parts of Riga; 3 - tectonic faults in the Caledonian structural complex; 4 - the Kalkugravas water spring; 5-Persistent Scatterer points on the Cirulisi fault; 6 - points of measurement of radon anomaly; 7 - radon survey profile. The sidebar shows points 14 and 15 on opposite sides of the Cirulisi fault.

\section{Modern vertical movements}

Using the Persistent Scatterer Interferometry method (PanGeo Project), an anomalous velocity of points 14 and 15 (Figure 5, on the tab) located on opposite sides of the Cirulisi fault was found at a distance of about $80 \mathrm{~m}$ from each other (Nikulins, 2017). These points move in opposite directions (Figure 6) at velocities of -11.6 $\mathrm{mm} /$ year (point $14, \mathrm{IP}=62392$ ) and $+13.8 \mathrm{~mm} /$ year (point $15, \mathrm{IP}=62371$ ), whereas an average background velocity in Riga of $\pm 1.5 \mathrm{~mm} /$ year (Nikulin, 2014).

The contrasting motions of these points on different sides of the Cirulisi fault indicate its geodynamic activation. The length of the Cirulisi fault is only $13 \mathrm{~km}$ and on the northeast edge it adjoins to the Olaine-Incukalns fault. At a length of about $9 \mathrm{~km}$, between Valdlauci and Stunisi, there is a powerful tectonic node formed by DobeleBabite, Cirulisi, Olaine-Incukans, Sauriesi and Bergi faults.

The Cirulisi fault's northern side is raised whereas southern side is lowered, that indicates the thrust fault regime, due to pressure from the North Atlantic to the southeast. 
Earlier it was already noted (Brangulis et al., 1984) that thrust regime is characteristic of the mechanism of the Olaine-Incukalns fault. Indirect confirmation of the thrust regime are the heights of two points located on the southwestern wing of opposite sides of the Cirulisi fault, at a distance of $1390 \mathrm{~m}$ between the points. The northern point has a height mark of $16.4 \mathrm{~m}$, whereas the southern point is $10.4 \mathrm{~m}$. The difference between elevations is slightly more than $6 \mathrm{~m}$.

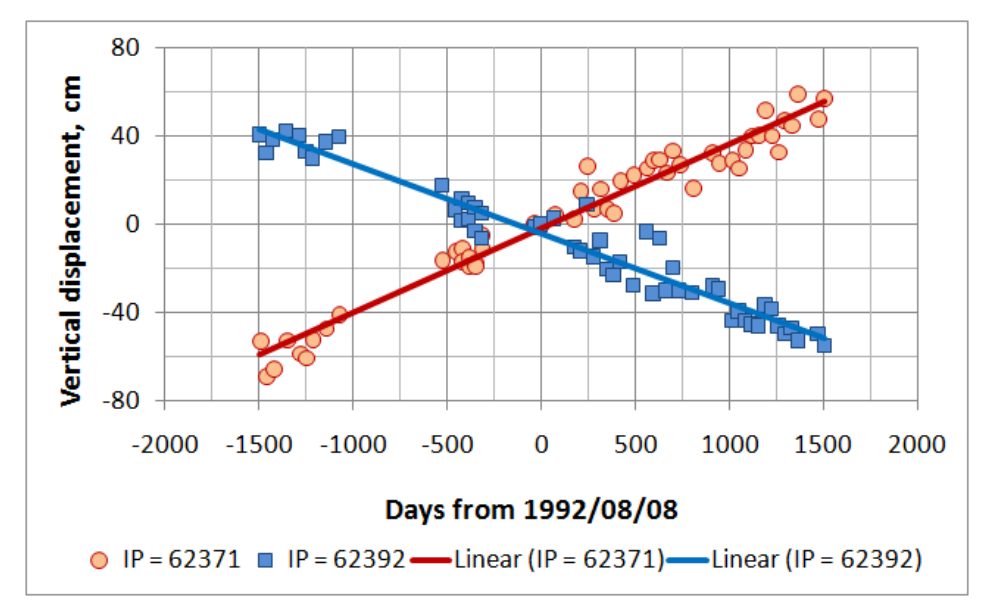

Fig. 6. Vertical displacements of PS points 62371 and 62392, located on different sides of the Cirulisi fault. The abscissa indicates the number of days since the beginning of the research on August 8, 1992.

The Cirulisi fault may have a small strike-slip component, however, there is no complete clarity in the relation of the type of this strike-slip. The azimuth of the maximum horizontal compression stress $S_{H \max }$, determined on the basis of the decision of the focal mechanism of the first Kaliningrad earthquake on September 21, 2004 (11:05:03 GMT) is $166^{\circ}$, and on the basis of the decision of the focal mechanism of the second Kaliningrad earthquake (13:32:31 GMT) is equal $157^{\circ}$ (Heidbach et al., 2016). In these cases, the Cirulisi fault will have a small left-lateral strike-slip component. Thus, the Cirulisi fault is prevailing thrust fault with a small strike-slip component. At the same time, the direction $S_{H \max }$ may differ from the values of the Kaliningrad earthquake sources obtained as a result of the decision of the focal mechanism. If the azimuth $S_{H \max }$ is less than $147^{\circ}$, then a right-lateral strike-slip component may appear in the thrust regime. This can affect the change in the geodynamic situation, contributing to the growth of tectonic stress in the area of the aforementioned tectonic node.

\section{Anomalies of radon concentration in the surface air}

The geodynamic activity of the Olaine-Incukalns fault was confirmed by the anomalous concentration of radon detected on the profile at the Sigulda area (Fig. 5).

One of the three test sites for investigation of anomalous concentration of radon was located here. In accordance with the results of studies of the subsurface radon concentration in Latvia based on the report of Gilucis in 2014, at the Sigulda site, an 
anomaly of increased radon concentration was detected at point number 12 (Figure 7) (Nikuliins, 2017a). Its value reached about $140 \mathrm{KBq} / \mathrm{m}^{3}$, which exceeds the concentration of radon at the neighboring observation points in 1.6 - 3 times.

The Olaine-Incukalns fault intersects the section between points 13 and 12, about 1 $\mathrm{km}$ long (Figure 5). These points are located on different sides of the Olaine-Incukalns fault. It is known that radon is an indicator of the continuity of the geological environment, the presence of faults and their activity (Spivak, 2014; Ge et al., 2014). Moreover, radon is considered as one of the possible precursors of earthquakes (Ge et al., 2014; Pulinets et al., 2015; Gregoričetal., 2012). A higher background level and bursts of high radon values are associated with an increase in voltage in the medium [Chyi et al., 2005].

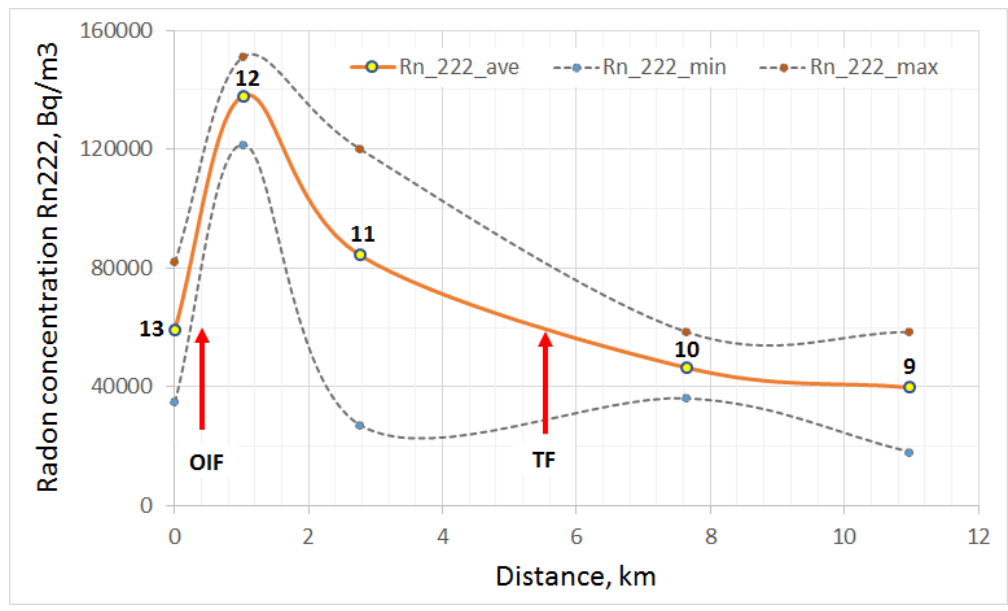

Fig. 7. Change in subsurface radon concentration along the profile crossing the Olaine-Incukalns fault. Designations of tectonic faults: OIF - Olaine-Incukalns; TF - Turaida.

At the Riga section, the observational posts do not cross the Olaine-Incukalns fault, but are located only to the north of it. Nevertheless, there is a tendency to increase the concentration of radon in the direction of the fault.

\section{Deformations of buildings and a geomorphological features in the tectonic zone formed by the Olaine-Incukalns and Bergi faults}

Deformations of buildings and structures (Figure 8), including recently constructed (Nikulins, 2017b), are additional factors that indicate the activity of deformation processes developing within the tectonic zone formed by the Olaine-Incukalns and Bergi faults

Deformations were revealed in the building of the supermarket "Prizma" (June 3, 2016), where changes in structural elements were observed. In the new building in the Dreilini area (September 2016), bearing columns have been damaged. Can note the slope of the house located on Malienas Street and the formation of large cracks in the walls of 
the houses located on Palsas Street (Figure 9). These buildings are located $100-400 \mathrm{~m}$ from the Olaine-Incukalns fault.

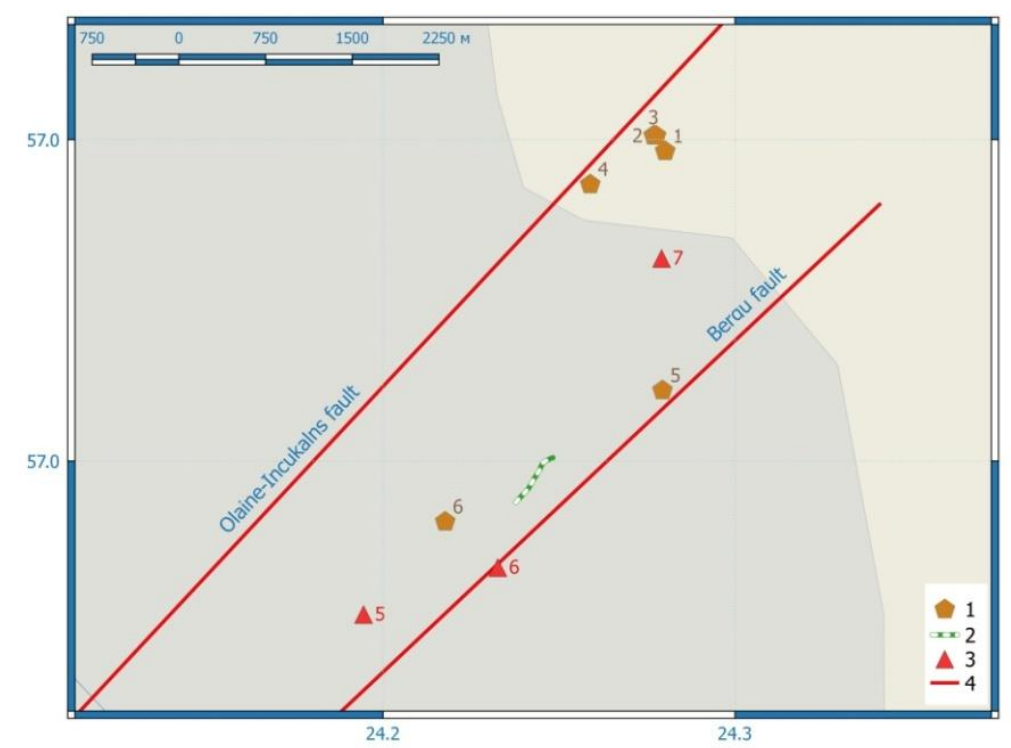

Fig. 8. Objects of deformation, macroseismics and morphology within the tectonic zone formed by Olaine-Incukalns and Bergi faults. Legend: 1 - deformation of buildings (1 - Malienas, 2 - Palsas 24, 3 - Palsas 26, 4 - Druvienas, 5 - Kaivas, 6 - supermarket "Prizma"); 2 - ravine; 3 - points of feeling of shocks on November 22, 2010 (points numbers is corresponds to Fig. 5); 3 - tectonic faults in the Caledonian structural complex.

In the area Mezciems (Druvienas street), the roof of a 5-storey residential building was damaged, as a result of clogging of piles on a construction site located 100 meters from it and the arisen vibration. Cracks were formed a width from $2 \mathrm{~mm}$ to $3-4 \mathrm{~cm}$. In a number of researches it is recommended to take into account influence of strengthening of vibration depending on an arrangement of a tectonic zone (Pilecka et al., 2017).

In the area of Ulbrokas street there is a gully (Figure 8), about $0.5 \mathrm{~km}$ long. It has an azimuthal direction close to the azimuthal direction of the Bergi fault. It's hardly a coincidence. It is known that in the zone of faults the geological medium has an increased fracture, it is fragmented and fragmentation contributes to the erosion process. Erosion increases in weakly consolidated soils, and also where there is a surface, uncontrolled flow of water. Gully may be associated with neotectonic activity, as confirmed by studies on the Indian platform (Raj et al., 1999). 

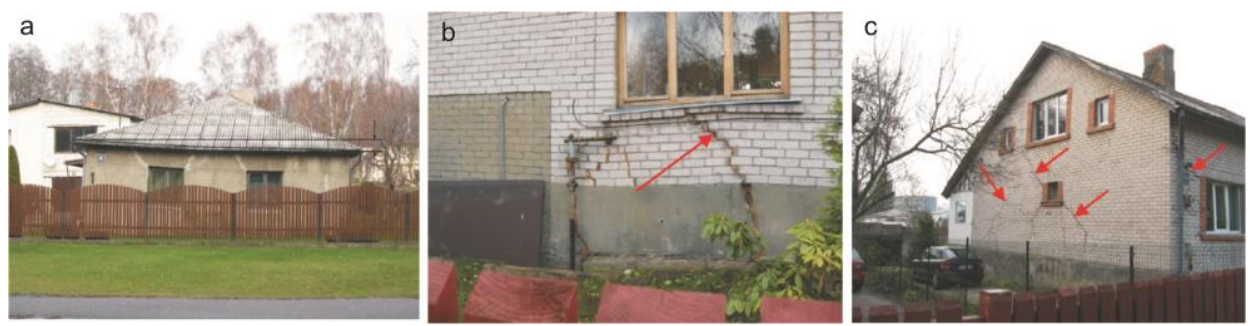

Fig. 9. Deformation of buildings near the Olaine-Incukalns fault (Jugla district, Riga). Designations: a - Malienas 28; b - Palsas 26; c - Palsas 24.

\section{Seismotectonic conditions in the area of Plavinas HPP}

The Plavinas HPP is the largest HPP in the EBR. In 1966, it was put into operation. In 1985, as a result of seismic surveys by report of Bebrish et al., tectonic faults were found in the crystalline basement and the Caledonian structural complex of the sedimentary cover. These faults form a graben-shaped structure (Figure 10), on the south-western edge of which there is the Plavinas HPP dam and the head part of the reservoir.

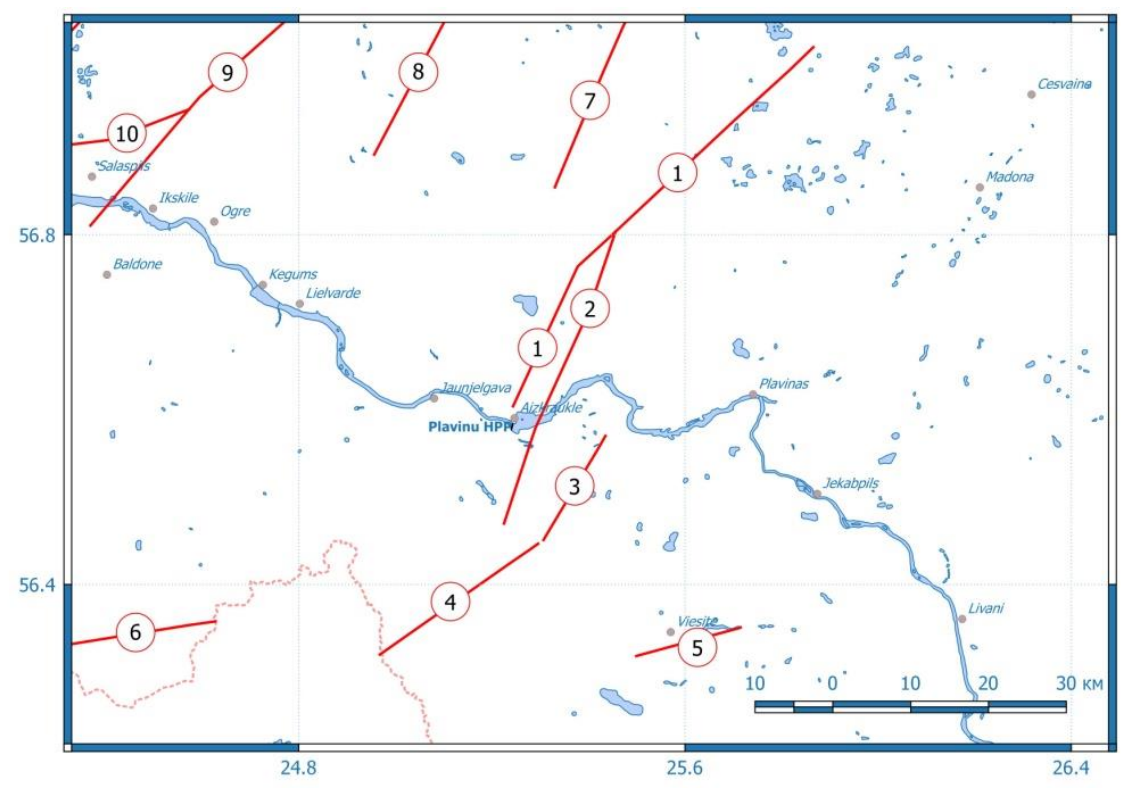

Fig. 10. Tectonic situation in the area of PlavinasHPP and reservoir. Designations of tectonic faults in the Caledonian structural complex: 1 - Piebalga, 2 - Aizkraukle, 3 - Sece, 4 - Erberge, 5 Viesite, 6 - Bauska, 7 - Erglu, 8 - Nitaure, 9 - Kekava, 10 - Sauriesi.

So, Plavinas HPP is located in the zone of geodynamic risk. This feature found a reflection in adverse endo genesis phenomena (supergene processes) associated with the 
development of suffosion processes and migration of fine grained sand in the Daugava valley near the Plavinu HPP (Dislere, 2007).
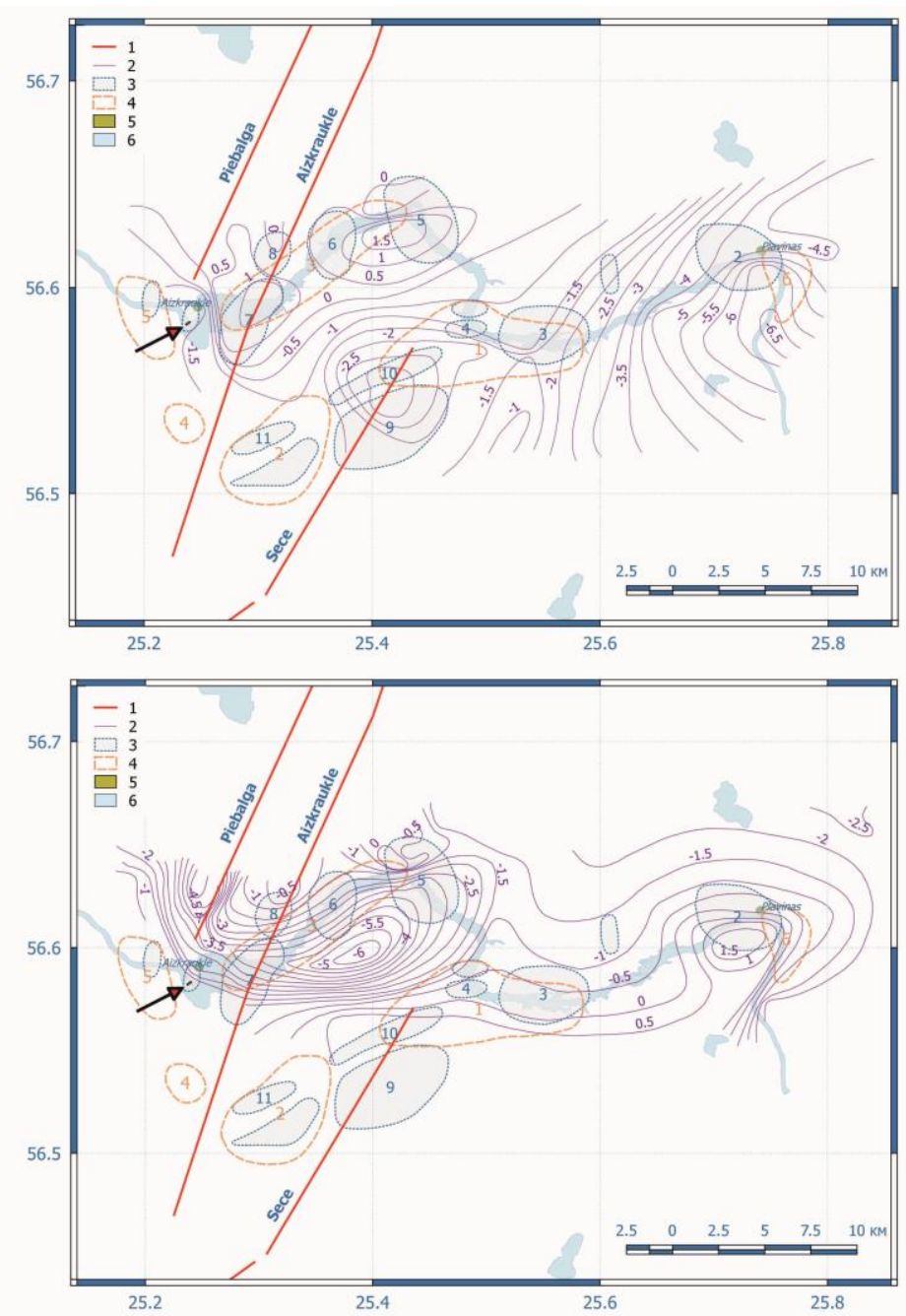

Fig. 11. Restructuring of modern movements of the Earth's crust until (1963 - 1965/1966) and after (1965 - 1968) filling the Plavinas reservoir (according to report of Aboltins, 1969). Designations: 1 - tectonic faults; 2 - velocities of modern vertical movements (mm/year); 3 - areas of distribution of Paleozoic, local, tectonic structures; 4 - areas of neotectonic uplifts; 5 - Dam of Plavinas HPP (arrow pointing); 6 - the reservoir of the Plavinas HPP and the river bed of the Daugava.

An investigations of modern vertical movements of the Earth's crust in the area of the Plavinas HPP showed that there was a significant change in the geodynamic regime after the filling of the reservoir. North of the dam, the rate of lowering reached $-5.5 \mathrm{~mm} /$ year close to the southwestern edge of the Piebalga fault, at a distance of $5 \mathrm{~km}$ from the dam (Figure 11, below), and in the south of the reservoir the rate of lowering increased to -6.0 
$\mathrm{mm} /$ year, at a distance of $\sim 8.5 \mathrm{~km}$ from the dam according to report of Aboltins in 1969 . Before the reservoir was filled, the lowering rates were correspondingly equal to -1.5 $\mathrm{mm} /$ year and - $3.0 \mathrm{~mm} /$ year (Figure 11, above). The dam at the Plavinas HPP is located on the Memelian Paleozoic, local, tectonic structure. To the west of this structure is located a neotectonic uplift (Figure 11, area 5).

After filling the reservoir, the movements of the Earth's crust in the area near of the town of Plavinas have changed dramatically, where the Daugava River makes a loop, turning sharply to the south. If before the filling of the reservoir $(1963-1965 / 1966)$ there were intensive subsidence at this area at a velocity of up to $-6.5 \mathrm{~mm} / \mathrm{year}$, then after filling the reservoir (1965 - 1968) this area began to rise with a velocity of up to 1.5 $\mathrm{mm} /$ year. As a result of investigations at the Plavinas geodynamic polygon (PGP), short-period oscillations of the earth's crust with a period of 5 to 6 years were also observed according to report of Aboltins in 1971.

Filling the reservoir has led to a significant changes of modern vertical movements of the Earth's crust in area of Plavinas HPP and reservoir. This restructuring was expressed in the activation of the Piebalga fault. The zone of the maximum velocity gradient of vertical movements practically coincides with the southwestern edge of the Piebalga fault (Figure 11, below). Earlier, the existence of separate blocks of the earth's crust in the vicinity of the PGP was noted according of Aboltins report in 1971.

The tectonophysical analysis of the stress-strain state of the Earth's crust in the area of the Plavinas HPP and the head part of the reservoir showed that irrespective of the direction of the main, horizontal stress $S_{H \max }$ in the range from $136.1^{\circ}$ to $165.5^{\circ}$ at North and northeast of the dam is located a region of subsidence, depression. This region has the shape of a circle (Figure 12). If $S_{H \max }$ increases then subsidence, depression is completely surrounded by a zone of uplifts.
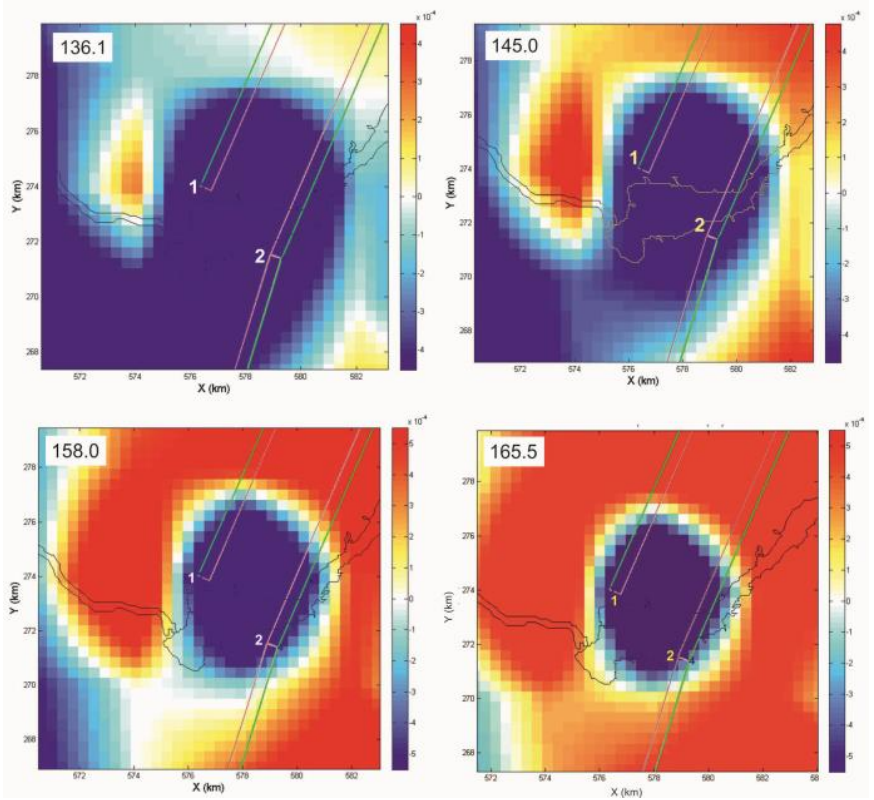

Fig. 12. Results of tectonophysical modeling of displacement of the Earth's surface in the region of the Plavinas HPP and the head part of the reservoir. Designations of faults: 1 - Piebalga, 2 Aizkraukles. The figures at the top left show the azimuth $S_{\text {Hmax }}$. 
However, the subsidence region exists only in the upper part of the section, to depths of the order of $1.0 \mathrm{~km}$, i.e. up to the top of the crystalline basement. For depth more than $1.0 \mathrm{~km}$, the subsidence area disappears, and in the downstream, in the vicinity of the dam of the Plavinas HPP, either a subsidence occurs $S_{H \max }$ at $136.1^{\circ}$ and $145.0^{\circ}$, or a rise $S_{\text {Hmax }}$ at $158.0^{\circ}, 165.5^{\circ}$.

Experimental results of investigations of the Earth's crust movement at the Plavinas geodynamic polygon performed in 1963-1968 showed that at the Plavinas HPP and at water reservoir area there are separate blocks of the earth's crust that reacted to a change in hydrostatic pressure during the filling of the reservoir.

The results of tectonophysical modeling showed the decisive role of the graben-like structure and the southwestern edge of the Piebalga fault in the formation of unstable geodynamic conditions in the form of a region of subsidence. The area of depression captures the sedimentary cover and the upper part of the crystalline basement. The tectonic forces of the global (from the North Atlantic spreading zone) and of the regional scale have a decisive influence.

\section{Discussions and conclusions}

Despite the typical view of the ancient cratons, as on territory with a "calm state in a seismic attitude" (Rustanovich, 1967), the facts indicate that in their territory unfavorable geodynamic conditions may exist. Numerous facts confirm the tectonic cause of macroseismic manifestations on November 22, 2010 in the zone formed by the Olaine-Incukalns and Bergi faults. Among them, the anomalous radon concentration, the activation of the tectonic zone formed by the Olaine-Incukalns and Bergi faults, expressed in the deformation of a number of buildings, the presence of geomorphological features (gully, the direction of which coincides with the Bergi fault), the anomalous movement of the Cirulisi fault edges in opposite directions. With great probability, we can state that these shocks could have been caused precisely by tectonic causes.

Estimation of the isostatic index allowed to detect a violation of the isostatic state and to determine the type of development of the Earth's crust. Taking into account that the DSS profile extends in the northwest of the Vidzeme Upland, it is possible to assume with certain probability that in the center of the Vidzeme Upland the value of isostatic index will be not less than $+6.0 \mathrm{~kg} / \mathrm{mm}^{2}$. Such a large deviation from isostatic equilibrium indicates disturbed geodynamic conditions within the Vidzeme Upland. The central part of the Vidzeme Upland continues to rise. The revealed anomalous values of the isostatic index were confirmed by experimental results. In particular, the results of the re-leveling carried out in 1935 - 1966 throughout the whole territory of Latvia indicate that in the Ieriki area, geodetic mark's velocity $V_{V}$ reached of a maximum value of $+3.5 \mathrm{~mm} /$ year according to report of Kovalevsky et al. in 1966. Modern data obtained in 2015 showed that the velocities of the vertical movements $V_{V}$ of the permanent GNSS stations of LatPos network (Fig. 1) are $+0.52 \mathrm{~mm} /$ year for Lielvarde (LVRD) and +0.30 $\mathrm{mm} /$ year for Lode (LODE) (Haritonova et al., 2015). The LODE station is located in the center of the Vidzeme Upland, and LVRD is located about $30 \mathrm{~km}$ to the south-west of the edge of the Vidzeme Upland. The zone of uplifts in the central part of Latvia is 
oriented parallel to the DSS profile the Soviet-Riga-Kohtla-Jarve, in the direction southwest-north-east.

A complex geodynamic situation exists in the vicinity of the Plavinas HPP and the head part of the reservoir. As a result of filling the reservoir, after 1965, the hydrostatic load on the earth's crust increased, which led to a change in the sign of the movements of individual blocks of the Earth's crust as a result of investigations at the Plavinas geodynamic polygon. As a result of seismic investigations in 1985 the Piebalga and Aizkraukle tectonic faults were discovered in the Caledonian structural complex and crystalline basement, the presence of which largely explained the results of tectonophysical modeling and depression wich was formed near the southwestern edge of the Piebalga fault.

Thus, the identified seismotectonic prerequisites of geodynamic hazards in the territory of Latvia lead to need more detailed studies of the mechanism of tectonic faults and the elucidation of their main elements. An equally important task is to estimate the maximum horizontal compression stress on the basis of indirect estimates and possibly direct measurements. At least the assessment of this parameter is very important for the Plavinas HPP area. A more detailed knowledge of these parameters and tectonophysical modeling will make it possible to develop a geodynamic model for the entire Earth crust of Latvia. LatPos GPS stations are a very important source of information about deformation of the Earth's crust. Taking into account a certain correction in their location, the efficiency of their use can be increased to assess the geodynamic state of the earth's crust of Latvia.

\section{List of abbreviations used}

EEC - Eastern European craton; DBNA - the divergent boundary of the North Atlantic; CBMS - the convergent boundary of the Mediterranean Sea; POWE - Phanerozoic orogen of Western Europe; EBR - East-Baltic region; TTZ - Teisseyre-Tornquist Zone; DSS - deep seismic sounding; Moho - the Mohorovičić discontinuity; $\Delta m$ - isostatic index; $\Delta g$ - gravitational anomaly; $Q$ - density of heat flow; $A_{N}$ - amplitudes of neotectonic movements; $V_{V}$ - velocity of modern vertical movements; InSAR Interferometric synthetic-aperture radar, PSI - Persistent Scatterer Interferometry; $S_{\text {Hmax }}$ - maximum horizontal compression stress; HPP - hydroelectric power plant; UGS underground gas storage.

\section{Acknowledgements}

The author expresses gratitude to the organizers of the 76th International conference of the University of Latvia "Geodynamics and geocosmic studies", participation in which allowed to prepare this article. 


\section{References}

Ankudinov S.A., BrioH.S., Sadov A.S.(1991). Deep structure of the Earth's crust on the territory ofthe Baltic States according to DSS data. The Belarusian Seismological Bulletin, issue1, 111 - 117 (in Russian).

Barberio M.D., Barbieri M., Billi A., Doglioni C., Petitta M. (2017). Hydrogeochemical changes before and during the 2016 Amatrice-Norcia seismic sequence (central Italy). Scientific Reports, 7:11735, 1 -12. https://www.nature.com/articles/s41598-017-11990-8.pdf Accessed April 6, 2018.

Bateson L., Novali F., Cooksley G. (2010). Terrafirma user guide. A guide to the use and understanding of Persistent Scatterer Interferometry in the detection and monitoring of terrainmotion. ESA GNES, 49 pp.

Brangulis A.P., Straume Y.A., Bendrup L.P., Birger A.Y., Birkis A.P., Brio H.S., Gavrilova A.V., Meyrons Z.V., Yushkevichs V.V. (1984). Geology of the Latvian SSR. Explanatory note to the geological maps of the Latvian SSR at a scale of 1: 500,000. 214 pp. (in Russian).

Brangulis A.J., Kanev S. (2002). Latvian tectonics. 50 pp. (in Latvian).

Chaudhuri H., Das N.K., Barman C., Iyengar A.N.S., Ghose D., Sen P., Sinha B. (2013). Network of Seismo-Geochemical Monitoring Observatories for Earthquake Prediction Researchin India. Acta Geophysica, vol. 61, issue 4, $1000-1025$.

Chyi L.L., Quick T.J., Yang T.F., Chen C.-H. (2005). Soil gas radon spectra and earthquakes. Terrestrial Atmospheric and Oceanic Scientific Journal, vol. 16, issue 4, 763 - 774.

Claesson L., Skelton A., Graham C., Dietl C., Morth M., Torssander P., Kockum I. (2004). Hydrogeochemical changes before and after a major earthquake. Geology, vol. 32, issue 8, 641 $-644$.

Dislere S. (2007). The regularities of the development of geodynamic processes and possibilities for their analysis. Geography Geology Environmental science. Collection of abstracts. Riga, 135 - 136 (in Latvian).

Faytelson A.Sh. (1973). Archimedean equilibrium of the Earth's crust. Isostasy. Ed. Artemiev M.E., Science, Moscow, $44-49$ (inRussian).

Garetsky R., Levkov E., Schwab G., Karabanov A., Aizberg R., Garbar D., Kockel F., Ludwig A.O., Lukke-Andersen H., Ostaficzuk S., Palienko V., Sim L., Sliaupa A., Sokolowski J., Stackebrandt W. (1999). Main Neogeodynamic features of the Baltic Sea depression and adjacent areas. Technika Poszukiwan Geologicznych. Geosynoptyka i Geotermia. Krakow. vol. 1 , issue $195,17-27$

Ge L., Zhao J., Luo Y. (2014). The research on earthquake radon anomalies. Journal of Geoscience and Environment Protection, 2, 38 - 40.

Gregoric A., Zmazek B., Dzeroski S., Torkar D., Vaupotic J. (2012). Radon as an Earthquake Precursor - Methods for Detecting Anomalies. Earthquake Research and Analysis - Statistical Studies, Observations and Planning, Dr Sebastiano D'Amico (Ed.), ISBN: 978-953-51-0134-5, In Tech, Available from: http://www.intechopen.com/books/earthquake-research-and-analysisstatistical-studiesobservations-and-planning/radon-as-earthquake-precursor-methods-fordetecting-anomalies

Haritonova D., Balodis J., Janpaule I., Morozova K. (2015).Earth's surface displacement from the GPS time series in Journal of Physics: Conference Series.

Heidbach O., Rajabi M., Reiter K., Ziegler M. (2016). World Stress Map 2016. GFZ Data Service. doi: 10.5880/WSM.2016.002.

Malakootian, M., Nouri, J. (2010). Chemical Variations of Ground Water Affected by the Earthquake in bam region. International Journal of Environmental Research, vol. 4, issue 3, $443-454$

Nikulin V. (1999). Correlation between isostatic anomalies and neotectonic movements in Latvia. Tehnika Poszukiwan Geologicznuch. Geosynoptyka i Geotermia. Krakow,vol. 1, issue 195, 68 $-76$. 
Nikulin V.G.(2014). Zones of geological hazard for Liepaja and Riga based on the results of remote sensing using the Persistent Scatterer Interferometry method. Society and Culture, Collection of Articles, Liepaja University, XVI,432 - 439 (in Russian).

Nikulins V. (2017a). Seismicity of the East Baltic region and application-orienred methods in the conditions of the low seismicity. Academic edition, University of Latvia, $291 \mathrm{pp}$.

Nikulins V. (2017b). Signs of the seismotectonic activity of the Olaine-Incukalns-Bergi fault zone. Applied Geological Surveys. University of Latvia.75th Scientific Conference. Thesis collection. $26-28$ (in Latvian).

Pilecka E., Stec K., Szermer-Zaucha R. (2017). The influence of the Klodnica fault tectonic zone on the degree of damage to buildings resulting from high magnitude tremors. Civil Engimeering, 7, $53-64$.

Pulinets S.A., Uzunov D.P., Karelin A.V., Davidenko D.V. (2015). Physical bases of generation of short-term earthquake precursors. Complex model of geophysical processes in the lithosphereatmosphere-ionosphere-magnetosphere system initiated by ionization. Geomagnetism and aeronomy, vol. 55, issue 4, 540 - 558 (in Russian).

Raj R., Maurya D.M., Chamyal L.S. (1999). Tectonic control on distribution and evolution of ravines in the Lower Mahi Valley, Gujarat. Journal of the Geological Society of India, vol. 53,issue 6, $669-674$.

Rezanov I.A., Faytelson A.Sh. (1973). The main directions in the evolution of the Earth's crust and its equilibrium. Isostasy. Ed. Artemiev M.E., Science, Moscow, 121 - 139 (in Russian).

Rustanovich D.N.(1967). Seismicity of the territory of the Turkmen SSR and the Ashkhabad earthquake of 1948. $96 \mathrm{pp}$ (in Russian).

Spivak A.A. (2014). Manifestation of fault zones in geophysical fields. Geodynamics \&Tectonophysics, vol. 5, issue 2, $507-525$ (in Russian).

Received April 9, 2018, revised March 13, 2019, accepted March 21, 2019

\section{Author's information}

V. N̦ikulins, Dr.geol., is seismologist of Latvian Environment, Geology and Meteorology Center. His professional interests include seismological monitoring, seismotectonics, geodynamics and engineering seismology. 